\title{
ANALISIS KESALAHAN SINTAKSIS DALAM TEKS LAPORAN HASIL OBSERVASI SISWA KELAS VII SMP NEGERI 17 MEDAN TAHUN PEMBELAJARAN 2017/2018
}

\author{
Priyo Utomo (utomopriyo813@gmail.com) \\ Fitriani Lubis (rianiavandi@gmail.com) \\ Universitas Negeri Medan
}

\begin{abstract}
ABSTRAK
Penelitian ini bertujuan untuk mengetahui dan mendeskripsikan (1) jenis-jenis kesalahan penggunaan kalimat (2) penyebab terjadinya kesalahan penggunaan kalimat (3) solusi terhadap kesalahan penggunaan kalimat. Hasil penelitian, yaitu (1) kesalahan sintaksis berupa penggunaan kalimat dari 36 teks terdapat sejumlah 66 kalimat yang mengandung kesalahan sintaksis penggunaan kalimat. Rincian kesalahan tersebut yaitu, kalimat tidak bersubjek, kalimat tidak berpredikat, kalimat tidak lengkap, antara predikat dan objek yang tersisipi, penghilangan konjungsi, penggunaan konjungsi yang berlebihan, penggunaan istilah asing, dan penggunaan kata tanya yang tidak perlu (2) faktor penyebab kesalahan sintaksis berupa penggunaan kalimat dalam teks laporan hasil observasi siswa meliputi: terpengaruhnya bahasa yang lebih dahulu dikuasainya, kekurangpahaman pemakai bahasa terhadap bahasa yang dipakainya, dan pengajaran bahasa yang kurang tepat atau kurang sempurna. (3) upaya yang dapat dilakukan untuk mengurangi kesalahan sintaksis berupa penggunaan kalimat yaitu: member contoh terlebih dahulu, meningkatkan penguasaan komptensi kaidah penulisan kalimat, memperbanyak latihan menulis, memberikan waktu yang cukup kepada siswa, dan menerapkan teknik koreksi yang tepat.
\end{abstract}

Kata Kunci: analisis kesalahan, sintaksis, dan teks laporan hasil observasi

\section{PENDAHULUAN}

Pembelajaran bahasa

Indonesia pada dasarnya menuntut siswa untuk mampu berbahasa dan bersastra. Belajar berbahasa sama halnya belajar berkomunikasi. Oleh karena itu, pembelajaran berbahasa dan sastra Indonesia di sekolah siswa diarahkan untuk meningkatkan kemampuan berkomunikasi baik secara lisan maupun tulis dengan baik dan benar. Menurut Setyawati (2013: 2), menyatakan bahwa "Pada 
bahasa lisan informasi yang disampaikan dapat diperjelas dengan menggunakan intonasi, gerakan anggota tubuh tertentu, dan situasi tempat pembicaraan itu berlangsung.

Sedangkan pada bahasa tulis unsurunsur bahasa yang digunakan cenderung tidak selengkap bahasa lisan. Oleh sebab itu agar informasi yang disampaikan secara tertulis menjadi lebih jelas, unsur-unsur bahasa yang digunakannya harus lengkap".

Salah satu Kompetensi Dasar (KD) dalam pembelajaran bahasa Indonesia dikelas VII adalah menyajikan teks laporan hasil observasi secara lisan dan tulis dengan memperhatikan kaidah kebahasaan (KD 4.8). Dalam Kompetensi Dasar (KD) 4.8 siswa dituntut harus mampu menyajikan atau memproduksi atau menghasilkan teks laporan hasil observasi baik secara lisan maupun tulis. Hal tersebut tentunya menuntut bahwa isi teks harus terdiri dari kalimat-kalimat yang sistematis sesuai dengan aturan tata bahasa Indonesia. Menurut Kemendikbud (2016: 129), “Teks laporan hasil observasi adalah teks yang berfungsi untuk memberikan informasi tentang suatu objek atau situasi, setelah diadakannya investigasi/penelitian secara sistematis."

Menurut Setyawati (2013: 16), "Analisis kesalahan merupakan sebuah proses yang didasarkan pada analisis kesalahan orang yang sedang belajar dengan objek (yaitu bahasa) yang sudah ditargetkan." Kesalahan berbahasa tidak hanya terdapat pada bahasa lisan tetapi juga terdapat pada bahasa tertulis. Bahasa tertulis terikat pada aturan-aturan kebahasaan, seperti ejaan, susunan, sistematika, dan teknik-teknik penulisan. Apabila siswa tidak memenuhi aturan-aturan kebahasaan tertulis, terjadilah kesalahan kebahasaan. Salah satu kesalahan berbahasa yang sering dilakukan oleh siswa pada kegiatan menulis adalah kesalahan pada tata cara penulisan kalimat.

Penelitian yang dilakukan oleh Sako (2017: 1532) hasilnya adalah kesalahan penggunaan kalimat diklasifikasikan menjadi sepuluh aspek. Pertama, penggunaan kalimat yang tidak bersubjek. Kedua, penggunaan kalimat yang tidak 
berpredikat. Ketiga, penggunaan kalimat yang tidak bersubjek dan tidak berpredikat (bunting). Keempat, penggunaan tanda tanya yang tidak perlu. Kelima, pengaruh struktur bahasa daerah. Keenam, penggunaan subjek ganda. Ketujuh, penggunaan kalimat yang tidak logis. Kedelapan, penggunaan kalimat ambigu. Kesembilan, penggunaan konjungsi berlebihan. Kesepuluh, penggunaan kalimat yang tidak paralel.

Permasalahan yang

dijelaskan di atas akhirnya membuat peneliti merasa tertarik untuk melakukan penelitian dengan judul "Analisis Kesalahan Sintaksis dalam Teks Laporan Hasil Observasi Siswa Kelas VII SMP Negeri 17 Medan Tahun Pembelajaran 2017/2018.”

\section{METODE PENELITIAN}

Metode yang digunakan dalam penelitian ini adalah metode deskriptif kualitatif. Dikatakan deskriptif karena penelitian ini mendeskripsikan data yang akan dianalisis yaitu kesalahan sintaksis berupa penggunaan kalimat dalam teks laporan hasil observasi siswa kelas VII SMP Negeri 17 Medan Tahun Pembelajaran 2017/2018. Sedangkan metode kualitatif digunakan untuk menguraikan konsep-konsep pemahaman yang berkaitan satu sama lain dengan menggunakan kata-kata atau kalimat yang berpedoman pada teori yang relevan.

\section{HASIL PENELITIAN DAN PEMBAHASAN}

\section{A. Hasil Penelitian}

Tabel 1

Kesalahan Sintaksis Berupa Penggunaan Kalimat Rekapitulasi

Kesalahan Sintaksis dalam Teks Laporan Hasil Observasi

Siswa Kelas VII SMP Negeri 17 Medan

\begin{tabular}{c|c|c|c}
\hline No & $\begin{array}{c}\text { Jenis Kesalahan Sintaksis Penggunaan } \\
\text { Kalimat }\end{array}$ & Jumlah & Persentase \\
\hline 1 & Kalimat Tidak Bersubjek & 2 & $3 \%$ \\
\hline
\end{tabular}




\begin{tabular}{c|l|c|c}
\hline 2 & Kalimat Tidak Berpredikat & 2 & $3 \%$ \\
\hline 3 & Kalimat Tidak Lengkap & 26 & $39,5 \%$ \\
\hline 4 & Penggandaan Subjek & - & - \\
\hline 5 & Antara Predikat dan Objek yang Tersisipi & 1 & $1,5 \%$ \\
\hline 6 & Kalimat Tidak Logis & - & - \\
\hline 7 & Kalimat yang Ambigu & - & - \\
\hline 8 & Penghilangan Konjungsi & 19 & $28,8 \%$ \\
\hline 9 & Penggunaan Konjungsi yang Berlebihan & 3 & $4,5 \%$ \\
\hline 10 & Urutan yang Tidak Paralel & - & - \\
\hline 11 & Penggunaan Istilah Asing & 11 & $16,7 \%$ \\
\hline 12 & Penggunaan Kata Tanya yang Tidak Perlu & 2 & $3 \%$ \\
\hline & $\quad$ Jumlah & 66 & \\
\hline
\end{tabular}

Berdasarkan tabel di atas dapat disimpulkan bahwa dari 36 teks yang sudah dianalisis terdapat 66 kalimat yang mengandung kesalahan sintaksis penggunaan kalimat. Secara rinci kesalahan tersebut yaitu, kalimat tidak bersubjek (2 kalimat persentase sebesar 3\%), kalimat tidak berpredikat (2 kalimat persentase sebesar 3\%), kalimat tidak lengkap (26 kalimat persentase sebesar $39,5 \%$ ), antara predikat dan objek yang tersisipi (1 kalimat persentase sebesar 1,5\%), penghilangan konjungsi (19 kalimat persentase sebesar 28,8\%), penggunaan konjungsi yang berlebihan (3 kalimat kalimat persentase sebesar 4,5\%), penggunaan istilah asing (11 kalimat kalimat persentase sebesar 16,7\%), dan penggunaan kata tanya yang tidak perlu (2 kalimat persentase sebesar 3\%).

\section{Faktor Penyebab Kesalahan Sintaksis dalam Penggunaan \\ Kalimat}

Faktor penyebab kesalahan sintaksis berupa penggunaan kalimat dalam teks laporan hasil observasi siswa meliputi: terpengaruhnya bahasa yang lebih dahulu dikuasainya, kekurangpahaman pemakai bahasa terhadap bahasa yang dipakainya, dan pengajaran 
bahasa yang kurang tepat atau kurang sempurna.

\section{Upaya yang Dapat Dilakukan} untuk Mengurangi Kesalahan Sintaksis Berupa Penggunaan Kalimat

Adapun upaya yang dapat dilakukan untuk mengurangi kesalahan sintaksis berupa penggunaan kalimat yaitu: memberi contoh terlebih dahulu, meningkatkan penguasaan komptensi kaidah penulisan kalimat, memperbanyak latihan menulis, memberikan waktu yang cukup kepada siswa, dan menerapkan teknik koreksi yang tepat.

\section{B. Pembahasan}

1. Kesalahan Sintaksis Berupa Penggunaan Kalimat

Tabel 2

Kalimat Tidak Bersubjek

\begin{tabular}{|c|c|}
\hline Bentuk y & Bentuk yang benar \\
\hline $\begin{array}{l}\text { (1) "Dari bentuknya yang } \text { unik } \\
\text { menunjukkan kekhasan dari buah } \\
\text { belimbing." (T7.P1.K2) }\end{array}$ & $\begin{array}{l}\text { (1a) Dari bentuknya yang } \text { unik } \\
\text { ditunjukkan kekhasan dari buah } \\
\text { belimbing. } \\
\text { (1b) Bentuknya yang unik } \\
\text { menunjukkan kekhasan dari buah } \\
\text { belimbing. }\end{array}$ \\
\hline $\begin{array}{l}\text { Kalimat-kalimat di atas } \\
\text { terlihat belum selesai karena belum } \\
\text { bersubjek. Subjek kalimat tersebut } \\
\text { tidak jelas atau kabur karena subjek } \\
\text { kalimat aktif tersebut didahului }\end{array}$ & $\begin{array}{l}\text { lain yang sejenis dengan preposisi } \\
\text { yang mengaburkan subjek adalah di, } \\
\text { di dalam, dalam, bagi, dengan, } \\
\text { sebagai, merupakan, kepada dan } \\
\text { pada. }\end{array}$ \\
\hline
\end{tabular}

preposisi dari dan untuk. Kata-kata

Tabel 3

\section{Kalimat tidak berpredikat}




\begin{tabular}{l|l}
\hline Bentuk yang salah & Bentuk yang benar \\
\hline $\begin{array}{l}\text { (3) "Khasiatnya yang baik untuk tubuh } \\
\text { membuatnya disukai banyak orang." } \\
\text { (T20.P1.K2) }\end{array}$ & $\begin{array}{l}\text { (3a) "Khasiatnya baik untuk tubuh } \\
\text { membuatnya disukai banyak orang." } \\
(3 b) \text { "Khasiatnya yang baik untuk tubuh } \\
\text { itu membuatnya disukai banyak orang." }\end{array}$ \\
\hline \multicolumn{1}{c}{ Kalimat tidak } & $\begin{array}{l}\text { penulis terlena dan lupa bahwa } \\
\text { kalimat yang dibuatnya belum }\end{array}$ \\
berpredikat disebabkan oleh adanya \\
keterangan subjek yang beruntun \\
atau terlalu panjang. Keterangan itu \\
diberi keterangan lagi, sehingga atau belum terdapat \\
predikat. Kalimat di atas terlihat \\
belumberpredikat.
\end{tabular}

Tabel 4

Kalimat Tidak Lengkap

\begin{tabular}{l|l}
\hline Bentuk yang salah & Bentuk yang benar \\
\hline (5) "Seperti plastik, kaca, dan lain- & (5) "Sampah anorganik adalah sampah \\
lain.” (T1.P2.K4) & yang tidak bisa membusuk, seperti \\
& plastik, kaca, dan lain-lain.” \\
\hline
\end{tabular}

Kalimat-kalimat di atas kalimat tempat bergantung anak merupakan kalimat yang susunannya kalimat tadi disebut induk kalimat.

dipenggal-penggal. Kalimat yang Penggandaan Subjek

dipenggal itu masih mempunyai Setelah dianalisis, tidak hubungan gantung dengan kalimat ditemukan sama sekali kesalahan lain (sebelumnya). Kalimat yang sintaksis berupa penggunaan kalimat memiliki hubungan gantung itu pada penggandaan subjek.

disebut anak kalimat. Sedangkan 
Tabel 5

Antara Predikat dan Objek yang Tersisipi

\begin{tabular}{l|l}
\hline Bentuk yang salah & Bentuk yang benar \\
\hline (31) "Museum sangat bermanfaat untuk & $(31)$ "Museum sangat bermanfaat untuk \\
tempat belajar tentang sejarah dan & tempat belajar sejarah dan hiburan." \\
hiburan." (T21.P1.K4) & \\
\hline
\end{tabular}

Dalam kalimat aktif transitif, yaitu kalimat yang memiliki objek. Verba transitif tidak perlu diikuti oleh preposisi sebagai pengantar objek. Dengan kata lain, antara predikat dan objek tidak perlu disisipi preposisi, seperti atas, tentang, dan akan.

Kalimat Tidak Logis
Setelah dianalisis, tidak ditemukan sama sekali kesalahan sintaksis berupa penggunaan kalimat pada kalimat tidak logis.

\section{Kalimat yang Ambigu}

Setelah dianalisis, tidak ditemukan sama sekali kesalahan sintaksis berupa penggunaan kalimat pada kalimat yang ambigu.

Tabel 6

\section{Penghilangan Konjungsi}

\begin{tabular}{|c|c|}
\hline Bentuk yang salah & Bentuk yang benar \\
\hline $\begin{array}{l}\text { (38) "Kelinci banyak dijadikan hewan } \\
\text { peliharaan, (...) bentuknya lucu dan } \\
\text { jinak membuatnya disukai masyarakat." } \\
\text { (T13.P2.K1) }\end{array}$ & $\begin{array}{l}\text { (38) "Kelinci banyak dijadikan hewan } \\
\text { peliharaan, karena bentuknya lucu dan } \\
\text { jinak membuatnya disukai masyarakat." }\end{array}$ \\
\hline $\begin{array}{l}\text { Dalam kaidah bahasa Indoneisa, } \\
\text { konjungsi jika, apabila, setelah, } \\
\text { sesudah, ketika, karena, dan } \\
\text { sebagainya digunakan sebagai }\end{array}$ & $\begin{array}{l}\text { ditinggalkan. Karena sudah merata } \\
\text { gejala tersebut digunakan di berbagai } \\
\text { kalangan, maka mereka tidak sadar } \\
\text { lagi kalau bentuk penghilangan itu } \\
\text { alah }\end{array}$ \\
\hline
\end{tabular}


Tabel 7

Penggunaan Konjungsi yang Berlebihan

\begin{tabular}{l|l}
\hline Bentuk yang salah & Bentuk yang benar \\
\hline (51) “Walaupun musang memiliki jenis & $(51)$ "Walaupun musang memiliki \\
yang berbeda, akan tetapi khusus untuk & banyak jenis, khusus musang panda \\
musang panda suka memakan apa & suka memakan apa saja.” \\
saja." (T5.P2.K2) & \\
\hline
\end{tabular}

\begin{tabular}{rrrrrr}
\multicolumn{2}{c}{ Kekurang } & cermatan & siswa & & penggunaan dua konjungsi sekaligus. \\
memakai & bahasa & dapat & Seharusnya konjungsi yang \\
mengakibatkan & & penggunaan & digunakan salah satu saja.
\end{tabular}

konjungsi yang berlebihan. Hal itu terjadi karena dua kaidah bahasa

\section{Urutan yang Tidak Paralel}

bersilang dan bergabung dalam

Setelah dianalisis, tidak sebuah kalimat. Siswa tidak ditemukan sama sekali kesalahan menyadari kalau bentuk-bentuk sintaksis berupa penggunaan kalimat kalimat di atas menggunakan pada urutan yang tidak paralel. padanan yang tidak serasi, yaitu

\section{Tabel 8}

\section{Penggunaan Istilah Asing}

\begin{tabular}{l|l}
\hline Bentuk yang salah & \multicolumn{3}{l}{ Bentuk yang benar } \\
\hline (54) "Handphone adalah salah satu alat & $\begin{array}{l}(51) \text { "Walaupun musang memiliki } \\
\text { elektronik yang biasa digunakan untuk } \\
\text { benyak jenis, khusus musang panda } \\
\text { suka memakan apa saja.” }\end{array}$ \\
\hline Pengguna bahasa Indonesia & bahasa ingin memperagakan \\
yang memiliki kemahiran & kebolehannya atau bahkan ingin \\
menggunakan bahasa asing tertentu & memperlihatkan intelektualnya pada \\
sering menyelipkan istilah asing & khalayak. Ketidaktahuan siswa \\
dalam pembicaraan atau tulisannya. & ketika menggunakan bahasa asing \\
Kemungkinannya adalah pemakai & dalam tulisannya kemungkinannya
\end{tabular}


terpengaruh oleh bahasa yang umum didengar dan disebutkan oleh banyak orang, sehingga siswa beranggapan bahwa bahasa tersebut adalah bahasa
Indonesia. Padahal kita tidak boleh mencampuradukkan bahasa Indonesia dengan bahasa asing.

Tabel 9

Penggunaan Kata Tanya yang Tidak Perlu

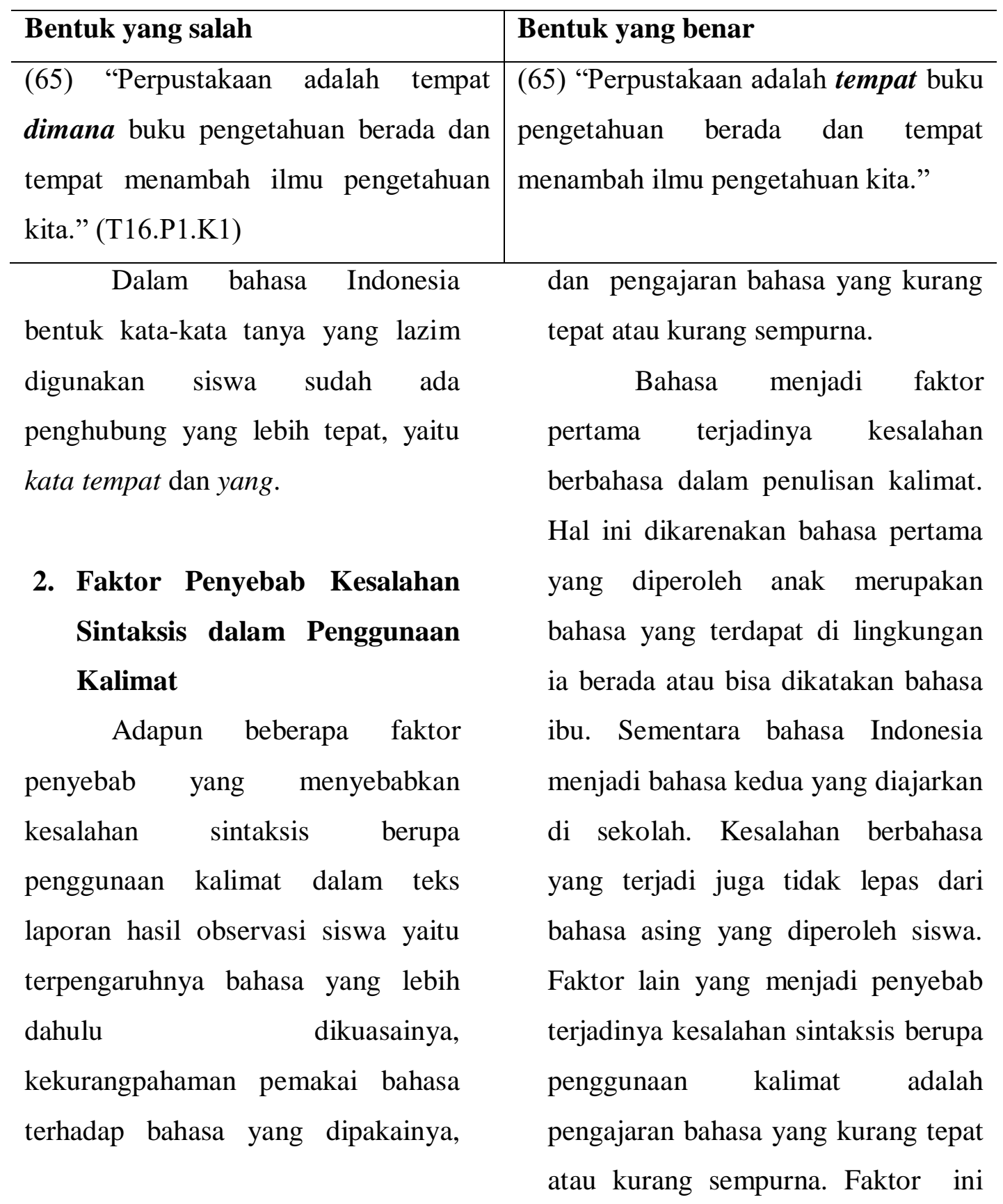


berkaitan dengan peran guru dalam menyalurkan ilmunya kepada siswa. Guru dituntut untuk mampu memahami dan menguasai konsep materi pembelajaran mengenai sintaksis atau tata kalimat yang baik dan benar.

\section{Upaya yang Dapat Dilakukan} untuk Mengurangi Kesalahan Sintaksis Berupa Penggunaan Kalimat

Komptensi guru dalam menguasai kaidah sintaksis berupa penggunaan kalimat juga harus diimbangi dengan praktiknya. Apabila guru tidak menyalurkan atau mengajarkan pengetahuannya kepada anak didiknya mengakibatkan tujuan pembelajaran menulis tidak tercapai. Oleh karaena itu, guru hendaknya menyalurkan segala pengetahuannya dengan memberikan contoh-contoh terlebih dahulu kepada siswa yang berkaitan dengan kaidah sintaksis berupa penggunaan kalimat yang baik dan benar baik lisan maupun tertulis. Contoh sederhana yang dapat diaplikasikan guru adalah dengan melalui percakapan di kelas atau di luar kelas, sehingga siswa yang selalu mendapat contoh akan sedikit demi sedikit mendapat pengetahuan dan menjadi paham akan penggunaan bahasa yang baku dan juga penulisan kalimat.

Penerapan teknik koreksi yang tepat juga termasuk salah satu upaya yang perlu dilakukan guru untuk mengurangi kesalahan sintaksis berupa penggunaan kalimat atau penulisan kalimat pada teks laporan hasil observasi siswa. Penerapan teknik koreksi yang dilakukan guru bahasa Indonesia masih belum maksimal. Hasil tulisan siswa hanya dinilai dan diberi coretan tanpa diberitahukan kesalahannya. Salah satu teknik koreksi yang tepat adalah teknik peer- correction. Teknik ini merupakan teknik pembelajaran yang mengarahkan siswa untuk mengoreksi kesalahan berbahasa pada hasil tulisan temannya dengan bantuan feedback atau umpan balik secara tidak langsung dari guru.

Pada kenyataan yang ada, kompetensi menulis yang diperoleh siswa masih rendah. Hal ini dikarenakan bahwa pengetahuan kaidah penulisan kalimat siswa 
masih kurang. Dengan menggunakan teknik peer-correction yang dilakukan guru dapat memicu siswa lebih aktif dalam belajar. Siswa lebih terlibat dalam pembelajaran dengan cara mengoreksi hasil pekerjaan teman-temannya.

\section{PENUTUP}

Hasil analisis data dan pembahasan dapat disimpulkan. (1) Kesalahan sintaksis berupa penggunaan kalimat dalam teks laporan hasil observasi siswa kelas VII SMP Negeri 17 Medan Tahun Pembelajaran 2017/2018 dari 36 teks terdapat sejumlah 66 kalimat yang mengandung kesalahan sintaksis penggunaan kalimat. Rincian kesalahan tersebut yaitu, kalimat tidak bersubjek ( 2 kalimat persentase sebesar 3\%), kalimat tidak berpredikat (2 kalimat persentase sebesar 3\%), kalimat tidak lengkap (26 kalimat persentase sebesar $39,5 \%$ ), antara predikat dan objek yang tersisipi (1 kalimat persentase sebesar 1,5\%), penghilangan konjungsi (19 kalimat persentase sebesar 28,8\%), penggunaan konjungsi yang berlebihan (3 kalimat kalimat persentase sebesar 4,5\%), penggunaan istilah asing (11 kalimat kalimat persentase sebesar 16,7\%), dan penggunaan kata tanya yang tidak perlu (2 kalimat persentase sebesar 3\%). (2) Faktor penyebab kesalahan sintaksis berupa penggunaan kalimat dalam teks laporan hasil observasi siswa meliputi: terpengaruhnya bahasa yang lebih dahulu dikuasainya, kekurangpahaman pemakai bahasa terhadap bahasa yang dipakainya, dan pengajaran bahasa yang kurang tepat atau kurang sempurna. (3) Upaya yang dapat dilakukan untuk mengurangi kesalahan sintaksis berupa penggunaan kalimat yaitu: memberi contoh terlebih dahulu, meningkatkan penguasaan komptensi kaidah penulisan kalimat, memperbanyak latihan menulis, memberikan waktu yang cukup kepada siswa, dan menerapkan teknik koreksi yang tepat.

Saran yang dapat disampaikan yaitu: (1) siswa hendaknya lebih meningkatkan kualitas penulisan kalimat agar kesalahan sintaksis berupa penggunaan dapat diminimalisir, dan 
(2) guru sebaiknya lebih Jurnal

Universitas

memperhatikan siswanya, dan Kanjuruhan Malang

mampu menjadi pilar teladan

berbahasa yang baik dan benar.

\section{DAFTAR PUSTAKA}

Kementerian Pendidikan dan

Kebudayaan. 2014. Buku

Guru Bahasa Indonesia

Wahana Pengetahuan untuk SMP/MTs Kelas VII. Jakarta:

Kementerian Pendidikan dan

Kebudayaan

- 2016. Bahasa Indonesia Edisi

Revisi untuk SMP/MTs Kelas

VII. Jakarta: Kementerian

Pendidikan dan Kebudayaan

Setyawati, Nanik. 2013. Analisis

Kesalahan Berbahasa

Indonesia: Teori dan Praktik.

Surakarta: Yuma Pustaka

Istinganah, Nurul. 2012. Analisis

Kesalahan Sintaksis pada

Karangan Narasi Ekspositori Siswa Kelas VIII SMP Negeri

1 Banguntapan, Bantul,

Yogyakarta. Yogyakarta:

Skripsi UNY

Setiawan, Dwi Agus. 2016. Analisis Kesalahan Sintaksis Bahasa Indonesia dalam Karangan Deskripsi Siswa Kelas VI SDN Kanigoro 02 Kecamatan Pagelaran yang Berbahasa Ibu Bahasa Madura. Malang: 